\title{
Is Diversification an Efficient or Safe Strategy? The Case of Perishable Food Crop Production Systems in Cameroon
}

\author{
Jules Rene Minkoua Nzie $^{1} \&$ Fidoline Ngo Nonga ${ }^{1}$ \\ 1 Groupe de Recherche en Environnement, Economie et Agroalimentaire (GREEA), FSEG/University of \\ Yaoundé II, Yaoundé, Cameroon \\ Correspondence: Jules Rene Minkoua Nzie, Groupe de Recherche en Environnement, Economie et \\ Agroalimentaire (GREEA), FSEG/University of Yaoundé II, P.O. BOX 1365, Yaoundé, Cameroon. E-mail: \\ minkouarene@yahoo.fr
}

Received: March 31, 2012 Accepted: June 2, 2012 Online Published: July 16, 2012

doi:10.5539/ijbm.v7n14p125 URL: http://dx.doi.org/10.5539/ijbm.v7n14p125

\begin{abstract}
The objective of this paper is to evaluate the relationship between informal risk management strategies, such as crop and nonfarm diversification, and technical efficiency of food crop producers in Cameroon. The methodology is based on (a) estimating the efficiency levels from a non parametric Data Envelopment Analysis (DEA) approach and (b) using statistics tools (Pearson correlation and mean tests) to assess the impact of diversification on efficiency. Data is obtained from tomatoes, potatoes and banana-plantain producers in 19 villages and peri-urban zones in the Center and West regions of Cameroon. Results indicate low levels of efficiency and a negative correlation between diversification practices and efficiency.
\end{abstract}

Keywords: technical efficiency, DEA, food crop, diversification, safety, Cameroon

\section{Introduction}

For agricultural households either selling and/or consuming their products, food crop production activity is vital for their survival because part of this production is consumed and the surplus sold in order to meet others needs. However, the literature reveals that these households often voluntarily choose when they face risks, to abandon the objective of efficiency in favor of strategic options of safety and precaution, such as diversification (Binswanger and Sillers, 1983; Walker and Jodha, 1986; Ellis, 1988; Bromley and Chavas, 1989; Larson, Anderson and Varangis, 2004; Dercon, 2005). According to Larson and Plessmann (2009), the differences in the implementation of risk management strategies can explain why productivities vary across households in the same region.

Hence, this paper attempts to answer the following question: to what extent can the implementation of risk management strategies (farm and non farm income diversification) affect the realization of food safety, through its impact on the efficiency levels of farmers? The answer to this question is important within the context of food crop production in Cameroon, characterized by levels of efficiency varying between 50\% and 69\% in the Center (Nyemeck, 1999) and 40\% and 75\% in the West (Wandji, 1999; Nkendah, 2000). Such efficiency levels suggest notable possibilities to increase production without any contribution of additional resources.

The present paper is organized as follows: we first present the literature review, and then the methodological framework and finally results generated.

\section{Literature Review}

In this section we first review analysis on diversification principles of agricultural household behavior analysis and models of choice with asset constraints in entry.

\subsection{Diversification Analysis}

Two forms of diversification are identified: farm diversification (or crop diversification) and farm income diversification (or diversification of activities) (Emrys and Ngau, 1991). The difference between both diversifications is based on the nature of the activities. According to Ilbery (1991), whereas farm diversification is located within the farm and implies primarily activities in the agricultural sphere, diversification of activities refers to income diversification coming from activities undertaken inside and outside the farm. 
Two main theoretical explanations of crop diversification exist. The first one holds that crop diversification emanates from demographic pressure (Lightfoot and Eddy, 1995). Authors such as Ruthenberg and Jahnke (1985) and Yung (1992), attest that crop diversification constitutes a practice rooted in subsistence agriculture. Later on, Ruthenberg and Jahnke (1985) affirm that the different types of crops cultivated are dictated by taste, even if their yields are low. Consequently, diversification is often regarded as "an important means to avoid an increased dependency on a small number of agricultural productions" (Wainwright, 1994). The second explanation conceives crop diversification as a strategy of risk minimization, in response to environmental risks (Goletti, 1999) and to economic fluctuations (Badouin, 1987; Alam, 1993; Goletti, 1999). This behavior is aimed at decreasing the probability of an unpredictable variation of annual income (Minnis, 1996).

According to Ellis (2000), the diversification of activities is defined as the process by which rural households build a growing portfolio of activities and various assets to survive and improve their standard of living. Based on this definition, Niehof (2004) envisages diversification as an important strategy which makes it possible to reduce vulnerability. For Delgado and Siamwalla (1997), the diversification of activities refers to the allocation of production assets among various income generating activities, carried out inside and out of the fields. Diversification of activities at the microeconomic level has two components (Von Braun, 1995). On the one hand, it can take place inside the farm (non crop production), as illustrated by the practice of breeding activities. On the other hand, it can be done out of the farm (nonfarm diversification), or it consists in the practice of extra agricultural activities defined by opportunities in the labor market. The extra agricultural activities can be informal or formal (related to wage-earning in the public or private). The informal activities are associated to small businesses operated by individuals in a given field (small shop, wood sale, etc), and can thus be compared to micro-enterprises. Consequently, we propose a typology of non agricultural diversification, distinguishing breeding, enterprise and wage-earning activities (see table 1).

Table 1. A typology of nonfarm income diversification of agricultural households in less developed countries

\begin{tabular}{ll}
\hline Type & Activities \\
\hline Breeding & cattle, fisheries, poultry, etc. \\
Enterprise (micro) & trade, hunting, blacksmith, traditional doctor \\
Wage-earning & civil servant, private worker \\
\hline
\end{tabular}

Source: Minkoua (2010).

According to Alderman and Paxson (1994), the diversification of activities constitutes one of the strategies of risk management used by households with the aim of reducing income variability and guaranteeing an acceptable minimum level of income. In other words, it is a strategy to smooth income (Dercon, 2002). Barret, Reardon and Webb (2001), apprehend overall diversification as a form of self-insurance.

\subsection{Principles of Agricultural Household Behavior Analysis}

The standard theory of production predicts a simple optimization behavior under constraint. Precisely we either maximize output subjected to a given level of costs or minimize production costs for a given level of output. Whatever the problem is, the theory reveals that rules of resource allocation and technological choices are identical. They obey the principle of duality. The resources being limited (because their relative availability is subjected to a cost), the producer is brought to use them in an efficient way, i.e. to achieve the highest possible level of output (or being given a fixed level of output, to use the lowest production costs).

However, several criticisms of the theory of profit maximization exist. One can quote the existence of a tradeoff between profit maximization and other objectives of the agricultural households, taking into account of the role of uncertainty (or risk) in the production decisions. Various models express these alternatives to the standard theory (see Mendola, 2007).

\subsubsection{Risk Aversion Models}

Two approaches are distinguished: the standard theory of the expected utility (Von Neumann and Morgenstern, 1944) and approaches in terms of the avoidance of catastrophes. According to the normative approach of the expected utility, all things being equal, a risk adverse household prefers a smooth flow of consumption to fluctuating inflows, which - in the contexts of incomplete markets of capital or less developed institutional arrangements- involves the choice of productive activities portfolio with low risk (Morduch, 1994). Regarding 
the approaches in terms of the avoidance of catastrophes or "safety first" model, the decision maker is supposed to ensure its own survival and consequently wants to avoid the risk that his/her income falls below a certain minimum subsistence level. However, the link between risk aversion and all gaps relative to economic efficiency is not clearly established because of the intervention of other factors such as market imperfections or constraints to access productive resources (Eswaran and Kotwal, 1989) which allow poor agricultural households to act as if they were risk averse.

\subsubsection{Models of Choice under Uncertainty}

One of the most important waves of the literature stresses the behavioral responses of the rural households vis-a-vis risk, that is, the ex ante mechanisms of risk management in the contexts where perfect markets do not exist. These constraints, in accessing resources affect the way in which the vulnerable agricultural households decide in connection with the resources allocation (Morduch, 1994). The ex ante risk management strategies implies that efforts should be made to design risks mitigation measures on risks faced by peasants, by integrating safeguard measures in the process of decision making. This entails adopting a more favorable portfolio of activities in terms of risks but (often) less favorable in terms of profit and efficiency (Morduch, 1994). There is a broad collection of empirical studies which provide the evidence of the conflict between risks and productive choices, leading to a deterioration of efficiency when safety is crucial (Rosenzweig and Binswanger, 1993; Morduch, 1993; Duflo, 2003). The results of these studies suggest that vulnerable peasants (and especially those who earn a good living and who have to lose more) will tend to prefer safety or a preserving strategy with low outputs, compared to a risky strategy with potential high outputs.

\subsubsection{Models of Choice with Asset Constraints in Entry}

These models identify prospects of risk and poverty, to analyze the production decisions of the agricultural household within the framework of efficiency. Thus, in a context of imperfect credit markets (where land can be used as guarantee), the rich farmer with land can easily acquire fertilizers and, if necessary, land and additional labour in order to efficiently use inputs. In addition, households with poor assets cannot enter high risky activities because they do not have enough assets. In order to reduce their income risk, these poor households will enter activities with low risk and poor yield (Eswaran and Kotwal, 1986; 1989). These results are not based on differences in risk preferences. At constant preference level, the poor one selects a portfolio with low risk and poor yield, whereas the rich farmers take a riskier set of activities.

At the end of the theoretical analysis, it has appeared that risk management behavior could be opposed to the pursuit of an objective of efficiency by the farmer. The following steps aim at assessing empirically the relation between informal risk management strategies with efficiency is outlined in the methodological framework.

\section{Methodological Framework}

The methodological framework is organized in three points. First, we briefly present the non-parametric DEA method used to estimate efficiency and diversification. Second, we use statistical tools to seek the effect of diversification on efficiency and third, we present the data.

\subsection{Method of Estimating Efficiency: Non Parametric DEA Approach}

This approach based on Farrel (1957)'s idea, is developed by Charnes, Cooper and Rhodos (1978) who invented the expression data envelopment analysis (DEA), meaning a non-parametric method of mathematical programming allowing one to estimate a production frontier. This model of Charnes, Cooper and Rhodos (1978) assumes constant returns to scale (CRS). Later, Banker, Charnes and Cooper (1984) proposed a more general version of the model by admitting varying return to scale (VRS).

The comparison of measures of technical efficiency with CRS and the VRS makes it possible to define a measure of efficiency of scale. The latter is worth 1 when the farm reaches its long run scale of production. This is a situation of competitive equilibrium where the profit is null. If not, it is in an intermediate situation where return to scale can be increasing or decreasing (Banker, Charnes and Cooper, 1984).

\subsection{Method of Measuring Diversification}

The following table describes empirically the two types of diversifications measured at the farm level (table 2). The main economic speculation is tomato, potato or plantain. 
Table 2. Types of diversification strategies measured in family farms within the areas studied

\begin{tabular}{ll}
\hline Types of diversification & Definition \\
\hline Crop diversification & Number of crops planted minus one; entire variable. \\
Diversification of activities & Variable with three modalities: $0=$ do not have any activity; $1=$ \\
& use breeding; $2=$ run external farm activity. Each modality can \\
& be transformed as binary variable. \\
\hline
\end{tabular}

Source: Minkoua (2010).

\subsection{Method of Assessing the Effect of Diversification on Technical Efficiency}

The evaluation of the determinants of efficiency can be made by several methods. We distinguish the statistical methods (the analysis of correlation variance, mean comparisons tests, restriction tests in the production functions) and the econometric methods. It is advisable within the framework of this research to adopt only the method which best characterizes the nature of the relation between diversification strategies and efficiency. The aim here not being to identify the all determinants of efficiency, the reasonable choice thus relates to the analysis of correlations (Feder, Just and Zilberman, 1985) and the mean comparison tests (Huang and Bagi, 1984; Kaboré, 1996) whose formal aspects are detailed in notes 1 and 2.

\subsection{Data}

Data is obtained from a survey carried out by Minkoua (2010) among 412 food producers of tomato, plantain and the potato, living in 19 villages and peri-urban areas of the Center and West regions of Cameroon between September and October 2006. The data was comprised of 244 farmers cultivating/selling tomato (133 in the West and 111 to the Center); 77 farmers cultivating/selling plantain (24 in the West and 53 in the Center) and 67 farmers cultivating/selling on potato in the West. Because the number of farmers cultivating/selling in the West (24) was not statistically significant, we examined only sales of plantain in the Center. This is same for the potato, whose transactions are analyzed only in the West. Table 3 gives statistical data on the variables used for the estimation of production frontier. It is the quantity produced in local measurement units (bag, basket, bunch), of the land size in hectares devoted to the production, of the volume of work expressed in terms of man/day.

Table 3. Basic statistics of outputs and inputs used for tomato, plantain and potato in the center and west regions

\begin{tabular}{|c|c|c|c|c|}
\hline Variables & Mean & Standard error & Min & Max \\
\hline & \multicolumn{4}{|c|}{ Tomato in Center } \\
\hline Quantity produced (baskets) & 204,94 & 252,18 & 2 & 1200 \\
\hline Land (ha) & 2,71 & 2,16 & 0,001 & 8,5 \\
\hline Labor (H/jour) & 6,28 & 5,68 & 0,75 & 30,75 \\
\hline \multirow{2}{*}{ Capital $\left(10^{3} \mathrm{f}\right.$ cfa $)$} & 124,83 & 141,30 & 5 & 1060 \\
\hline & \multicolumn{4}{|c|}{ Tomato in West } \\
\hline Quantity produced (baskets) & 160,11 & 249,14 & 3 & 1500 \\
\hline Land (ha) & 0,98 & 0,89 & 0,025 & 5 \\
\hline Labor (H/jour) & 4,02 & 2,89 & 1 & 14,75 \\
\hline \multirow[t]{2}{*}{ Capital $\left(10^{3} \mathrm{f}\right.$ cfa $)$} & 139,42 & 149,40 & 5 & 1080 \\
\hline & \multicolumn{4}{|c|}{ Plantain in Center } \\
\hline Quantity produced (bunches) & 265,02 & 512,03 & 4 & 3000 \\
\hline Land (ha) & 1,60 & 1,41 & 0,02 & 7 \\
\hline Labor (H/jour) & 5,64 & 4,40 & 0,75 & 20,75 \\
\hline \multirow[t]{2}{*}{ Capital $\left(10^{3} \mathrm{f}\right.$ cfa $)$} & 30,41 & 35,12 & 0 & 200 \\
\hline & \multicolumn{4}{|c|}{ Potato in West } \\
\hline Quantity produced (bags) & 39,16 & 98,76 & 2 & 750 \\
\hline Land (ha) & 0,84 & 0,97 & 0,05 & 6 \\
\hline Labor (H/jour) & 4,48 & 2,90 & 1 & 14,75 \\
\hline Capital ( $\left.10^{3} \mathrm{fcfa}\right)$ & 145,86 & 307,55 & 6,5 & 2400 \\
\hline
\end{tabular}

Source: Minkoua (2010). 
These variables are similar to those which are used for the estimate of the agricultural production frontier in less developed countries (see Nyemeck, 1999 for a bibliographical review). It is advisable to describe these various variables that one can distinguish in outputs and inputs.

\section{i. Description of outputs}

They are the levels of production in local measurement units of the various cultures obtained by the surveyed producers. The levels of production of tomato (baskets), plantain (bunch) and potato (bags of 100kgs) are rather different between the producers taking into consideration their rather high standard deviation.

\section{ii. Description of inputs}

They are the traditional inputs of agricultural production: land, capital and the labour. The input labour is measured as Men/day on the basis of calculation of assets at the level of each family farm. This calculation is based on weights defined by the Food and Agricultural Organization (FAO) where an adult man=1; an adult woman adult $=0.75$ and; a child and an old person $=0.5$. Only the permanent family laborers are considered. The descriptive statistics indicate on average relatively low levels of the factor labor whatever the crop.

As for the input capital, it is estimated for the agricultural season considered in each farm. Capital is measured in thousands of francs CFA and is determined by the sum of the expenditure supported in the current year for the purchase of materials and those devoted to the purchase of inputs (manures, products plant health, etc) used in the land plots. The statistics of this variable show levels of investment in capital, on average, in the same order for tomato in the Center, tomato and potato in the West, but relatively low for the plantain.

For the input land, measured in hectares, one observes the use, on average, of small plots in the West while in the center, the producers have relatively large surfaces. The computed values of the standard deviations are weak indicating a quasi similar behavior of surface allocation in each area.

\section{Results and Discussions}

The results are declined in two shutters: the first shutter evaluates the levels of efficiency obtained by the farm owners of the studied zones; the second shutter appreciates the effect of the informal risk management strategies, which are crop diversification and the diversification of activities on the levels of efficiency.

\subsection{Technical Efficiency Levels of Family Farms}

The distribution of these levels of efficiency is given in the table 4 under the CRS and VRS assumptions.

Table 4. Distribution of levels of technical efficiency of farmers

\begin{tabular}{lcccc}
\hline Levels of technical efficiency in \% & Tomato in Center & Tomato in West & Plantain & Potato in West \\
\hline & & CRS assumption & & \\
Mean & 26 & 21 & 21 & 20 \\
First quartile & 6.35 & 5.5 & 3.2 & 5.3 \\
Median & 13.7 & 11.6 & 6.8 & 11 \\
Third quartile & 29.15 & 23.1 & 22.2 & 19.25 \\
Min & 0.4 & 0.4 & 0.2 & 0.9 \\
Max & 100 & 100 & 100 & 100 \\
& & VRS assumption & & \\
Mean & 34 & 31 & 29 & 30 \\
First quartile & 8.7 & 6.6 & 4.7 & 7 \\
Median & 17 & 17.7 & 9.8 & 13.8 \\
Third quartile & 51.15 & 38.5 & 45.3 & 40.8 \\
Min & 0.4 & 0.5 & 0.2 & 0.9 \\
Max & 100 & 100 & 100 & 100 \\
Size & 111 & 133 & 53 & 67 \\
Student's t (paired) & -4.0345 & -5.3438 & -3.5897 & -2.5134 \\
Pr (T> t) & 0.0000 & 0.0000 & 0.0000 & 0.0000 \\
\hline
\end{tabular}

Source: Minkoua (2010). 
Globally, the median values for technical efficiency under CRS are significantly different, and in particular lower, than the median values for technical efficiency under VRS. Indeed, the Student t-statistics calculated on paired observations indicate a negative value which is lower than the critical value of $t$ (unilateral) for each crop.

It appears for the 111 producers of tomato of the Center that, the mean level of technical efficiency under CRS and VRS are respectively $26 \%$ and $34 \%$. In other words, an efficient use of all factors would respectively involve a saving in cost of $74 \%$ and $66 \%$ at a constant level of production. For tomato producers of the West, the mean level of efficiency under CRS and VRS are respectively $21 \%$ and $31 \%$. Regarding plantain producers, it appears that their average level of technical efficiency is $21 \%$ and $29 \%$ respectively under CRS and VRS. As for the potato owners, the mean level of technical efficiency is $20 \%$ and $30 \%$ respectively under CRS and VRS.

In addition, the total analysis of the dispersion shows that $25 \%$ of the least efficient producers (first quartile), whatever the crop, have a level of technical efficiency lower than $6.35 \%$ when admitting CRS. Under the VRS, the $25 \%$ the least efficient have a level of technical efficiency lower than $8 \%$. This means that, there are possibilities to increase the level of production by more than $92 \%$ for the least efficient producers. With regard to the $25 \%$ most efficient (third quartile), they have a technical level of efficiency for both assumptions between $22 \%$ and $46 \%$. This implies that the level of production of the latter can be obtained by an optimal reduction of costs around $78 \%$ to $54 \%$.

At the end of this statistical assessment on the distribution of the technical efficiency levels of tomato, plantain and potato producers, we cannot prevent ourselves from noticing that there are serious problems of inefficiencies in the various production activities. One counts only 5.66\%, $13.21 \%$ and $5.66 \%$ of producers of plantain who respectively have the best practices (technical efficiency) under CRS and VRS methods, whatever the assumption made on returns to scale. For the potato producers, $4.48 \%, 17.91 \%$ and $4.48 \%$ of them have the best practices under CRS and VRS methods, whatever the assumption made on returns to scale. As for the tomato farms in the Center, it appears that $7.21 \%, 16.22 \%$ and $7.21 \%$ of producers respectively present the best practices under CRS and VRS methods, whatever the assumption made on returns to scale. Whereas for tomato producers from the West, $3.76 \%, 12.78 \%$ and $3.76 \%$ among them respectively appear technically efficient under CRS and VRS methods, whatever the assumption made on returns to scale. It is thus advisable to explain such low performance levels. These low levels of inefficiency of perishable food crop, rather lower than those of storable food crop (Nyemeck et al, 2004), can be explained by a weak use of chemical fertilizers (Nkamleu and Adesina, 2000), or linked to a bad use of inputs (Nyemeck and Nkamleu, 2006), which constitute strong constraints for the rather demanding market-gardening productions in treatment in the plots.

\subsection{Appreciation of the Effect of Diversification Strategies on Efficiency}

Table 5 shows coefficients of Pearson's correlation between the levels of efficiency under CRS and VRS respectively and strategies adopted by the producers.

Table 5. Correlation between level of efficiency and diversification strategies

\begin{tabular}{|c|c|c|c|c|}
\hline & \multicolumn{4}{|c|}{ Correlation coefficients of Pearson $(P$-values at $5 \%)$} \\
\hline & Tomato in Center & Tomato in West & Plantain & Potato in West \\
\hline & \multicolumn{4}{|c|}{ CRS assumption } \\
\hline Crop diversification & $0.041(0.335)$ & $-0.054(0.269)$ & $-0.29^{* *}(0.017)$ & $-0.038(0.81)$ \\
\hline \multicolumn{5}{|l|}{ Diversification of activities } \\
\hline Not any & $0.002(0.491)$ & $-0.042(0.317)$ & $-0.070(0.310)$ & $-0.013(0.458)$ \\
\hline Breeding & $-0.124(0.098)$ & $-0.039(0.329)$ & $0.132(0.173)$ & $0.012(0.461)$ \\
\hline External farm activities & $0.082(0.196)$ & $0.078(0.187)$ & $-0.044(0.377)$ & $0.002(0.492)$ \\
\hline & \multicolumn{4}{|c|}{ VRS assumption } \\
\hline Crop diversification & $-0.026(0.391)$ & $0.000(0.496)$ & $-0.26^{* *}(0.030)$ & $-0.009(0.472)$ \\
\hline \multicolumn{5}{|l|}{ Diversification of activities } \\
\hline Not any & $0.022(0.411)$ & $0.041(0.320)$ & $-0.076(0.295)$ & $0.037(0.384)$ \\
\hline Breeding & $-0.149^{*}(0.059)$ & $-0.003(0.486)$ & $0.091(0.259)$ & $-0.054(0.333)$ \\
\hline External farm activities & $0.078(0.208)$ & $-0.003(0.486)$ & $0.005(0.487)$ & $0.012(0.461)$ \\
\hline
\end{tabular}

Source: Minkoua (2010). ${ }^{(*)}$ Significant at $10 \% ;{ }^{(* *)}$ significant at $5 \% ;{ }^{(* *)}$ significant at $1 \%$. 
The analysis of results in table 5 can be carried out in relation to each type of diversification. When compared to crop diversification, we note a negative correlation between levels of diversification and efficiency of the producers under CRS and VRS. However, one observes an ambiguity for the tomato producers in the Center, where one can note a negative correlation (coefficient of Pearson= -0.026) under VRS, but a positive (coefficient of Pearson=0.041) under CRS, between efficiency and crop diversification. However, these coefficients are not significant. The negative correlation between crop diversification and efficiency is significantly confirmed at a threshold of $5 \%$ with the plantain producers at a Pearson coefficient levels equal to -0.292 and -0.260 respectively under CRS and VRS. This finding specific to plantain can be related to Nkendah (2000) who finds that farming systems in which plantain seems to be the main crop, are more efficient than farming systems in which plantain is indifferently associated with other food crops.

As for the correlation between the diversification of activities and the efficiency of producers, one observes that it is rather weak, negative for most producers who carry out a secondary activity ( 9 over 16 cases, and non significant under CRS and VRS. This result suggests that there is a complete disconnection between the practice of other activities and the technical level of efficiency carried out in the family farm. It also confirms the prevailing psychology where the producers attempting to practice diversification, because of existence of entry costs (Dercon, 2002), perceive diversification as a means to meet family needs rather than an opportunity to adopt better practices. However it is interesting to know if there is efficiency between the producers who have distinct secondary activities.

Table 6 compares using Student's t, levels of efficiency carried out according to the type of activity practiced by the producers.

Table 6. Comparison of mean levels of efficiency between types of diversification activities

\begin{tabular}{llcrr}
\hline & \multicolumn{4}{c}{ Student $\mathrm{t}(p$-values $)$} \\
\cline { 2 - 5 } & Tomato in Center & Tomato in West & Plantain & Potato in West \\
\hline \multirow{2}{*}{ Not any versus breeding } & $2.761^{* * *}(0.005)$ & $0.216(0.830)$ & $-0.804(0.438)$ & $-0.104(0.917)$ \\
Not any versus external farm & $-0.687(0.497)$ & $-0.777(0.440)$ & $0.117(0.908)$ & $-0.069(0.945)$ \\
Breeding versus external farm & $-2.382^{* *}(0.012)$ & $-0.705(0.485)$ & $0.722(0.480)$ & $0.052(0.958)$ \\
& & \multicolumn{4}{c}{ VRS assumption } \\
Not any versus breeding & $3.319^{* * *}(0.001)$ & $0.596(0.556)$ & $-0.616(0.550)$ & $0.414(0.680)$ \\
Not any versus external farm & $-0.627(0.535)$ & $0.189(0.850)$ & $-0.150(0.883)$ & $0.074(0.940)$ \\
Breeding versus external farm & $-2.754^{* * *}(0.005)$ & $-0.414(0.681)$ & $0.346(0.733)$ & $-0.341(0.735)$ \\
\hline
\end{tabular}

Source: Minkoua (2010). ${ }^{(*)}$ Significant at $10 \% ;{ }^{(* *)}$ significant at $5 \% ;{ }^{(* *)}$ significant at $1 \%$.

The results of table 6 confirm the analysis of the preceding correlation, because the means difference test does not indicate any significant difference between the levels of efficiency obtained under distinct types of activity. The exception is made, however, with the tomato owners in the Center for which a significant difference of levels of efficiency between producers who have no activity of diversification and those who in addition to farming practice breeding and between the producers who practice the breeding and those which carry out external family farm activities. In particular, the student $t$-statistics for a unilateral test show that the mean efficiency of tomato producers in the Center who do not have any secondary activity is significantly higher than the average efficiency of the producing stockbreeders under CRS and VRS (t Student respectively equal to 2.761 and 3.319 under CRS and VRS). In the same way the producer/stockbreeders appear less powerful than those who practice other external farm activities under CRS and VRS (t Student respectively equal to -2.382 and -2.754 under CRS and VRS). The test also states that tomato producers in the Center without any secondary activity are significantly as powerful as the producers who have an external farm activity.

\section{Conclusion}

At the end of this research, it is advisable to point out the lesson that can be drawn from the analysis of the linkage between the informal risk management strategies and the individual performances of farmers. 
The results obtained on the levels of efficiency showed that the farmers are characterized by a substantial technical inefficiency, whatever the assumption on returns to scale. Thus, it appears that there is a gap of considerable inefficiencies between the average producer and the perfectly efficient producer. In addition, the results indicated a negative correlation between the levels of efficiency and agricultural diversification (at a 5\% level significance for the producers of plantain). This negative correlation is also observed between levels of efficiency and most practiced types of secondary activities. However, it is non significant. The test of means difference does not indicate a significant difference in efficiency between various types of activity of diversification, except for the case of the tomato producers in the Center region. In this region, producers who do not diversify their activities prove to be more efficient.

Broadly, these results confirm the theoretical predictions: the strategies of informal risk management, such as agricultural diversification and the diversification of activities penalize the technical efficiency of producers' agricultural if they give priority to safety. A focus should be made on the implementation of more formal risk management tools and the diffusion of production techniques enabling food crop producers to improve their levels of efficiency.

\section{References}

Alam, S. (1993). Diversification or Specialization in Agricultural Production Activities. Economic Affairs, 38, 84-88.

Alderman, H., \& Paxson, C. (1994). Do the Poor Insure? A Synthesis of the Literature on Risk and Consumption in Developing Countries. In International Economics Association, Moscow Meeting, Proceedings, 4.

Badouin, R. (1987). L'analyse Economique du Système de Production en Agriculture. Cahiers Sciences Humaines, 23(3-4), 357-375.

Banker, R. D., Charnes, A., \& Cooper, W. W. (1984). Some Models for Estimating Technical and Scale Efficiency in Data Envelopment Analysis. Working Paper, Carnegie Mellon University, Pittsburgh, Pa.

Barrett, C. B., Reardon, T., \& Webb, P. (2001). Nonfarm Income Diversification and Household Livelihood Strategies in Rural Africa: Concepts, Dynamics, and Policy Implications. Retrieved from http://inequality.cornell.edu/publications/working_papers/Barrett-Reardon-Webb_IntroFinal.pdf

Binswanger, H. P., \& Sillers, D. A. (1983). Risk Aversion and Credit Constraints in Farmers' Decision Making: A Reinterpretation. Journal of Development Studies, 20, 5-21. http://dx.doi.org/10.1080/00220388308421885

Bromley, D., \& Chavas, J. (1989). On Risk, Transactions, and Economic Development in the Semiarid Tropics. Economic Development and Cultural Change, 37, 719-736. http://dx.doi.org/10.1086/451757

Charnes, A., Cooper, W. W., \& Rhodes, E. (1978). Measuring the Efficiency of Decision Making Units. European Journal of Operation Research, 2, 429-444. http://dx.doi.org/10.1016/0377-2217(78)90138-8

Delgado, C. L., \& Siamwalla, A. (1997). Rural Economy and Farm Income Diversification in Developing Countries. IFPRI, MSSD Discussion paper No 20.

Dercon, S. (2002). Income Risk, Coping Strategies and Safety Nets. World Bank Research Observer, 17(2), 141-66. http://dx.doi.org/10.1093/wbro/17.2.141

Dercon, S. (2005). Vulnerability: a Micro Perspective. Retrieved from http://www.economics.ox.ac.uk/members/stefan.dercon

Duflo E. (2003). Poor but Rational. Massachusetts Institute of Technology.

Ellis, F. (1988). Peasant Economics: Farm Households and Agrarian Development. Cambridge University Press.

Ellis, F. (2000). Rural Livelihoods and Diversity in Developing Countries. Oxford: Oxford University Press.

Emrys, E. H., \& Ngau, P. (1991). Rural Urban Relations, Household Income Diversification and Agricultural $\begin{array}{lllll}\text { Productivity. In Development and Change, 22, 519-545. } & \text {. }\end{array}$ http://dx.doi.org/10.1111/j.1467-7660.1991.tb00424.x

Eswaran, M., \& Kotwal, A. (1986). Access to Capital and Agrarian Production Organisation. Economic Journal, 96, 482-498. http://dx.doi.org/10.2307/2233128

Eswaran, M., \& Kotwal, A. (1989). Credit as Insurance in Agrarian Economies. Journal of Development Economics, 31(1), 37-53. http://dx.doi.org/10.1016/0304-3878(89)90030-8 
Farrell, M. J. (1957). The Measurement of Productive Efficiency. Journal of the Royal Statistical Society, CXX(Part 3), 253-290. http://dx.doi.org/10.2307/2343100

Feder, G., Just, R. E., \& Zilberman, D. (1985). Adoption of Agricultural Innovations in Developing Countries: A Survey. Economic Development and Cultural Change, 33(2), 255-298. http://dx.doi.org/10.1086/451461

Goletti, F. (1999). Agricultural Diversification and Rural Industrialization as a Strategy for Rural Income Growth and Poverty Reduction in Indochina and Myanmar. IFPRI, MSS Discussion paper No 30.

Huang, C. J., \& Bagi, F. S. (1984). Technical Efficiency in Individual Farms in Northerwest Indian. Southern Economic Journal, 51, 108-115. http://dx.doi.org/10.2307/1058325

Ilbery B. W. (1991). Farm diversification as an adjustment strategy on the urban fringe of the West Midlands. Journal of Rural Studies, 7, 207-18. http://dx.doi.org/10.1016/0743-0167(91)90085-7

Kaboré, T. S. (1996). Innovations Techniques et Efficacité Economique dans les Systèmes de Production des Provinces du Bulkiemdé et du Sanguié au Burkina Faso. Thèse de Doctorat 3ème cycle, CIRES, Abidjan.

Larson, D. F., \& Plessmann, F. (2009). Do Farmers Choose to be Inefficient? Evidence from Bicol. Journal of Development Economics, 90, 24-32. http://dx.doi.org/10.1016/j.jdeveco.2007.04.003

Larson, D. F., Anderson, J. R., \& Varangis, P. (2004). Policies on Managing Risk in Agricultural Markets. World Bank Research Observer, 19, 199-230. http://dx.doi.org/10.1093/wbro/lkh022

Lightfoot, D. R., \& Eddy, F.W. (1995). The construction and configuration of Anasazi pebble mulch gardens in the northern Rio Grande. American Antiquity, 60, 459-470. http://dx.doi.org/10.2307/282259

Mendola, M. (2007). Farm Household Production Theories: A Review of "Institutional" and "Behavioral" Responses. Asian Development Review, 24(1), 49-68.

Minkoua JR. (2010). Effets de l'Instabilité des prix sur le comportement des offreurs: le cas des produits vivriers non stockables au Cameroun. Thèse de doctorat $\mathrm{Ph} \mathrm{D}$, Université de Yaoundé II.

Minnis, P. E. (1996). Notes on Economic Uncertainty and Human Behavior in the Prehistoric North American Southwest. In Tainter J. A., \& B. B. Tainter (Eds.), Evolving Complexity and Environmental Risk in the Prehistoric Southwest, Addison Wesley, Reading, MA, 57-78.

Morduch, J. (1993). Risk, Production, and Saving: Theory and Evidence from Indian Households. Harvard University, Cambridge.

Morduch, J. (1994). Poverty and Vulnerability. American Economic Review, 84(2), 221-225.

Niehof, A. (2004). The Signification of Diversification for Rural Livelihood Systems. Food Policy, 29, 321-338. http://dx.doi.org/10.1016/j.foodpol.2004.07.009

Nkamleu, G. B., \& Adesina A. A. (2000). Determinants of Chemical Input use in Peri-urban Lowland Systems: Bivariate Probit Analysis in Cameroon. Agricultural Systems, 63, 111-121. http://dx.doi.org/10.1016/S0308-521X(99)00074-8

Nkendah, R. (2000). Les Conditions Agro-économiques d'une Intensification Agricole au Cameroun: Le Cas de la Banane Plantain dans le Système Vivrier de la Province de l'Ouest. Thèse de 3ème Cycle, CIRES, p. 252.

Nyemeck, B. J. (1999). Systèmes de Cultures et Efficacité Economique au Cameroun: Une Approche du Genre dans la Culture du Maïs et de l'Arachide dans la Province du Centre. Thèse de doctorat, CIRES.

Nyemeck, B. J. Tonyé, J., Wandji, N., Nyambi, G., \& Akoa, M. (2004). Factors Affecting the Efficiency among Smallholder Farmers in the Slash and Burn Agriculture Zone in Cameroon. Food Policy, 29, 531-545. http://dx.doi.org/10.1016/j.foodpol.2004.07.013

Nyemeck, B. J., \& Nkamleu, G. B. (2006). Potentiel de Productivité et Efficacité Technique du Secteur Agricole en Afrique. Canadian Journal of Agricultural Economics, 54(3), 361-377. http://dx.doi.org/10.1111/j.1744-7976.2006.00055.x

Rosenzweig, M. R., \& Binswanger, H. P. (1993). Wealth, Weather Risk and the Composition and Profitability of Agricultural Investments. Economic Journal, 103, 56-78. http://dx.doi.org/10.2307/2234337

Ruthenberg, H., \& Jahnke, H. E. (1985). Innovative Policy for Small Farmers in the Tropics: The Economics of Technical Innovations for Agricultural Development. Oxford: Clarendon Press.

Von Braun, J. (1995). Agricultural Commercialization: Impacts on Income and Nutrition and Implications for 
Policy. Food Policy, 20(3), 187-202. http://dx.doi.org/10.1016/0306-9192(95)00013-5

Von Neuman, J., \& Morgenstern, O. (1947). Theory of Games and Economic Behavior. N.J.: Princeton University Press.

Wainwright, H. (1994). Export Diversification through Horticulture: Kenya-a Case Study. Outlook on Agriculture, 23, 41-45.

Walker, T., \& Jodha, N. (1986). How Small Farm Households Adapt to Risk. In Hazell P., C. Pomareda \& A. Valdés (Eds.), Crop Insurance for Agricultural Development. Johns Hopkins University Press, Baltimore.

\section{Notes}

Note 1. Pearson correlation test

This test is used when we have an independent quantitative variable (or binary discrete one) $X$ and a dependent quantitative variable $Y$. If one wants to establish a link between $X$ and $Y$, measure the intensity of this linkage or infer the existence of a correlation within a population, one determines a correlation coefficient,

$$
r=\frac{\operatorname{COV}(X, Y)}{\sigma(X) \sigma(Y)}
$$

The test hypotheses are as follows:

$H 0: \rho=0$ and $H 1: \rho>0$ ou $H 1: \rho<0$

One can build a statistic $r$ such as

$$
t=\frac{|r|}{\sqrt{\frac{\left(1-r^{2}\right)}{n-2}}}
$$

which follows under the null hypothesis a Student distribution with $n-2$ degree of freedom.

Note 2. Mean difference test

Let $X_{1}$ and $X_{2}$ denote two normal distributions with means $\mu_{1}$ and $\mu_{2}$, and standard errors $\sigma_{1}$ and $\sigma_{2}$. One tests:

H0: $\mu_{1}=\mu_{2}$ against H1: $\mu_{1} \neq \mu_{2}$ at risk $\alpha$.

One uses the Student test (in its more general version).

One sets out two samples with sizes $n_{1}$ and $n_{2}$, empirical means $\bar{x}_{1}$ and $\bar{x}_{2}$ and standard errors $s_{1}$ and $s_{2}$. If standard errors $\sigma_{1}$ are $\sigma_{2}$ are not known, and the sample sizes $n_{1}$ and $n_{2}$ are both greater than 30, one computes $t_{c a l}=\frac{\mu_{1}-\mu_{2}}{\sqrt{\frac{s_{1}^{2}}{n_{1}-1}-\frac{s_{2}^{2}}{n_{2}-1}}}$. One reject H0 at risk $\alpha$ if $t_{c a l} \notin\left[-t_{1-\alpha / 2}, t_{1-\alpha / 2}\right]$, where the value $t_{1-\alpha / 2}$ is read on the statistics' table. 